Civil Justice Quarterly 2007

ADR AND SCOTTISH COMMERCIAL LITIGATORS: A STUDY OF ATTITUDES AND EXPERIENCE

Bryan Clark, Charles Dawson.

This article analyses the aims and key findings of a recent, questionnaire-based research project carried out by the authors into the experiences and attitudes of commercial litigators in Scotland towards Alternative Dispute Resolution (ADR) processes. The study uncovered a small but significant measure of generally successful commercial mediation practice in scotland and revealed a legal profession that in the main was well-disposed towards ADR and its role within it. The research suggests that much still remains to be achieved, however, in terms of court-referral of mediation, legal professional body promotion, effective marketing to clients and further research regarding the suitablilty of mediation to different case-types if commercial mediation is to move from the sidelines into the mainstream.

\title{
Introduction
}

This article analyses the findings of a recent, questionnaire-based empirical study [FN3] that the authors have recently completed into the attitudes, experiences and awareness of Scottish commercial lawyers to ADR. This paper represents an exposition of the aims of the research, carried out between August and september 2005, and an examination of its main findings.

At the time the research was conducted, it had been 10 years since one of the present authors conducted the first empirical study into ADR in scotland. [FN4] At that juncture ADR was clearly at an embryonic stage of its development. While *229 revealing an enthusiasm for adoption of ADR techniques in different dispute areas, this early research suggested that ADR practice in Scotland remained somewhat thin on the ground.

Over the last decade or so, ADR has made steady if unspectacular strides, particularly in such areas as matrimonial [FN5] and community matters. [FN6] Despite the fact that recent times have seen the inception of a host of new commercial mediation providers in scotland such as Core Mediation [FN7] and Catalyst Mediation, [FN8] it has been suspected that commercial ADR's development has remained somewhat stagnant and in particular fallen behind the comparable growth seen in 
England and Wales. [FN9] Learned articles expounding the virtues of ADR in all sorts of dispute resolution areas in scotland have been rife of late. [FN10] In short, it is claimed that unlike traditional forms of dispute resolution, ADR may be quick, cheap, harmonious, confidential and conducive to party empowerment. The apparent disappointing state of affairs regarding commercial ADR in Scotland then may seem somewhat perplexing.

One factor that it has been argued will be key to the development of $\mathrm{ADR}$ in Scotland is the reaction of lawyers thereto. Given lawyers' traditional role in handling disputes on behalf of their clients, legal professionals clearly act as gatekeepers to dispute resolution fora. [FN11] The responses of lawyers are therefore crucial in charting the future development of commercial ADR in Scotland. Previous studies have hence called for research into lawyers' interaction with ADR to be undertaken. [FN12] Against this backdrop, the purpose of the study was to examine Scottish commercial litigation lawyers' awareness, experience and attitudes relative to ADR. [FN13] The research thus endeavoured to identify key policy issues relative to commercial ADR's development, in addition to painting a picture of Scottish commercial litigation lawyers' current interaction with ADR. [FN14]

Breakdown of Respondents

From a sample frame of 459, 140 responses were returned, representing a response rate of 30.5 per cent. Of the 140 respondents to the survey, 90 were solicitors, 24 were advocates and 26 were solicitor advocates. Only nine respondents were accredited mediators. In terms of when respondents had been admitted into practice, this is illustrated (by number of respondents) by Table 1 below.

Table 1

Before 19600

1960 s 2

1970 s 28

$1980 \mathrm{~s} 50$

$1990 \mathrm{~s} 50$

$2000+8$

No response 2 
Unlike the case with previous Scottish research which canvassed the views of lawyers with interests and involvement in ADR, [FN15] the study's purpose was to gauge the views and experiences of commercial litigators in general towards ADR. In any such study, there is a danger that those with a vested interest in promotion of the area in question are more likely to respond. While the results of this research must be read in this light, the fact that the vast majority of study respondents were not mediators and the majority of respondents had no direct experience of ADR, tempers this concern somewhat.

Knowledge of ADR

The study sought first to elicit respondents' knowledge of different ADR processes. The question was phrased in the following way: "which of the following forms of ADR could you explain to a client if asked?" Respondents were then asked to indicate their ability to describe the following processes: "mediation"; "early neutral evaluation"; "mini-trial" and "other (please state)". While levels of awareness may have been lower among nonrespondents, a stark result of the research was that all respondents claimed to be able to describe mediation to their clients. [FN16] Although it is impossible from this response to ascertain what respondents perceived mediation to entail, this confidence in ability to describe the process to clients seems to fly in the face *231 of received wisdom concerning a general lack of awareness of ADR amongst the Scottish legal fraternity. [FN17]

Other ADR processes did not fare so well. Only 24 respondents (17.4 per cent) felt able to explain early neutral evaluation and a mere 14 respondents (10.1 per cent) said they could explain mini-trial. Some other forms of ADR were alluded to by respondents, such as "ACAS procedures", "expert determination", "conciliation", "on-site neutral", "dispute panel" and "online dispute resolution".

Training in ADR

Lack of adequate training (alongside regulation) has been identified as a barrier to ADR development and sub- 
standard or variable training provision may raise questions regarding quality assurance. [FN18]

Training can be provided by various means, including programmes leading to accreditation as mediators, educational courses upon ADR in general or skills provision for representing parties in mediation, "inhouse" training or university provision. Respondents to the study were asked to indicate which, if any, of the above they had engaged in. Despite the fact all respondents felt able to describe the mediation process to clients, some 57 respondents (40.7 per cent) had no training in ADR. This fact may raise questions as to nontrained lawyers' perceptions of what the mediation process entails; particularly in light of previous English research which found that lawyers often harboured vague notions about mediation and perceived the process as synonymous with typical lawyer negotiations. [FN19]

Some 63 respondents (45 per cent) had attended external training courses on ADR and 17 (12.1 per cent) had received accreditation as mediators. The figure who had trained as mediators is less than that revealed in comparable research in England and Wales, in which 22 per cent of respondents had received such training by 2001 . [FN20] In addition, 40 respondents (28.6 per cent) had received training "in-house".

The most startling result in respect of training was that only five respondents ( 3.6 per cent) indicated that they had received training in the course of university studies. Many respondents would have attended degree or diploma studies prior to the development of ADR processes in Scotland. Indeed, of the five respondents who reported exposure to ADR education in their university days, none had entered the profession prior to the 1990s. Previous research in Scotland had been critical of the lack of training provision offered by $\star 232$ universities. [FN21] Educational ADR provision may have increased of late, but remains patchy at best. [FN22]

\section{Experience of ADR}

The study then sought to gauge the experiences of respondents in ADR. Virtually all reported ADR processes that parties had been involved in were mediation. This factor, coupled with the high awareness of mediation and limited knowledge of other ADR processes suggested that in the main when respondents discussed ADR, they were referring to mediation.

Factors in Recommending ADR to a Client 
In reviewing the potential development of civil ADR in Scotland, a recent scottish Executive research report [FN23] indicated that a key question concerned ADR's appropriateness to different dispute types. It has been recognised by even the most ardent ADR proponents that mediation is no panacea and will not always be suitable-for example, where an injunction or judicial precedent is sought. [FN24] Other factors such as dispute type, the financial value at stake and attitudes of, and relationship between disputants may also be relevant in determining when ADR processes such as mediation are appropriate. Against this backdrop, study respondents were given a list of factors and asked that if they had ever made recommendations to a client to attempt ADR, whether each factor was either "always relevant"; "often relevant"; "sometimes relevant"; "rarely relevant"; or "never relevant" to the decision to recommend. [FN25] Ninety-seven respondents (69.3 per cent) had recommended participation in ADR to their clients.

Two commonly touted benefits of mediation are that of low costs and quickness of settlement. It has been suggested, however, the relative cost-effectiveness of mediation is not so clear cut. [FN26] In particular, it has been claimed that in civil mediation in England and Wales, early case preparation requirements mean that the process involves a front loading of costs so that although resolution may be speedier than litigation, mediated settlement is in fact no cheaper. [FN27] Respondents to the study, however, clearly viewed there to be cost savings attendant to ADR participation. Some 77 respondents to this question (79.4 per cent) said that "a reduction in legal costs for their clients" *233 was either "always relevant" or "often relevant". Similarly, 82 respondents ( 84.5 per cent) indicated that "reaching a speedier settlement" was either "always" or "often" a relevant factor. Another factor of potential importance is privacy. While "privacy" was only identified as being "always" or "often" relevant by 34 respondents (35.1 per cent), it was noted as "sometimes" relevant by a further 38 respondents (39.2 per cent). Commercial sensitivities will fluctuate on a case-by-case basis and it is no surprise that the applicability of this factor varied.

The ability of mediation to engender creative solutions, beyond the reach of court remedies, is a perceived potential benefit of the process. The extent that mediation may actually achieve creativity of settlement in practice, however, can be questioned. For example, a study of commercial and construction mediations in England and Wales indicated that creative settlements were reached by mediation in a mere 7 per cent of cases. [FN28] From our survey it was not possible 
to glean the extent that creative settlements were in fact reached in mediations respondents were party to. Respondents expressed a clear view, however, that the potential for creativity may be an important factor in recommending ADR to their clients. Some 61 respondents (62.9 per cent) said that this factor was either "always" or "often" relevant to the decision to recommend ADR to a client, while a further 23 (23.7 per cent) indicating it was "sometimes" relevant.

Linked to creativity of settlement is the issue of preserving existing business relationships. A key feature of mediation across all dispute spheres is that the consensual nature of the process may be more appropriate where the parties are in (or wish to facilitate) a continuing relationship. It is trite to remark that the adversarial nature of the litigation process may render it unlikely that parties will be able to work together post-settlement. In this sense, "enabling continuation of a business relationship" was seen as "always" or "often relevant" by 54 respondents ( 55.7 per cent) and "sometimes relevant" by a further 27 respondents (27.8 per cent) in advising their clients to attempt ADR.

Tactical Motives

A factor that may stifle the development of mediation is the fear that the opposing party may harbour less than altruistic motives for their involvement therein. In Brooker and Lavers' study of construction mediation 50 per cent of respondents reported "some element of strategic deployment of mediation" and suggested that "reaching settlement is not always the prime motivation for agreeing to mediate and not all ... clients attend mediation in good faith". [FN29]

As has been noted, [FN30] lawyers south of the border have embraced ADR at least in part because of the primacy afforded mediation under the post Civil Procedural Rules regime and the cost sanctions that might be levied against *234 those who unreasonably refuse to attempt mediation. What this may entail then is an influx of parties attending mediations, but some perhaps under duress. This fact heightens the prospect of tactical use of the process.

It might be speculated that in a purely voluntary system of mediation, such as that in scottish commercial disputes, when parties do attend they would more likely do so with a genuine desire to reach settlement. If we are to take respondents to the study at face value, it would appear that cynical approaches may be rarer in Scotland than south of the border. For example, "the opportunity to gain information on the other side's case" 
was considered "always" or "often relevant" by only 17 respondents (17.5 per cent). A further 30 respondents (30.9 per cent) reported, however, that it may be "sometimes relevant".

ADR processes may be also used to pursue tactical aims other than settlement, which nonetheless seem more legitimate than early discovery of the other side's case. In the study, in response to a question as to how relevant "the prospect of assessing the risk of continuing a dispute" was, 68 respondents (70.1 per cent) thought this was "sometimes", "often" or "always" relevant. This represents a stronger response than found in respect of those who stated that gaining information on the other side's case was a relevant factor. There is a fine line to be drawn, however, between gauging the risk in continuing a dispute as opposed to assessing the strength of an opponent's case. Clearly the latter has an influence on perceptions of the former. It may be that respondents were more willing to reveal a desire to gain knowledge about their own case, as, unlike ascertaining information about the other side's case, this appears a more legitimate aim.

In any case, tactical use of mediation must be read against what occurs in traditional means of dispute resolution. The earlier procedural aspects of litigation often involve the pursuit of such knowledge, with a view to finding an appropriate settlement range. So while mediation purists may balk at this behaviour, it should hold few surprises.

Weakness in a Client's Case

Allied to tactical deployment of mediation is the notion that recourse to ADR may be more relevant where a party's case is weak from a legal perspective. It may be speculated that where a party and/or their representative believes they have a strong case, they may be more likely to seek recourse through litigation. [FN31] Such an argument, however, is predicated upon the idea that legal rights are paramount in the overall context of the dispute at hand. By contrast, parties may prefer a resolution that best meets their business interests. Hence, parties with strong legal cases may favour mediation in an attempt to head off the deleterious consequences of escalation of the dispute. Against this backdrop it is notable that only 21 study respondents (21.6 per cent) stated that *235 "a weakness in a client's case" was either "always" or "often relevant" with a further 39 (40.2 per cent) stating the factor was "sometimes relevant". 
Factors in Declining the Use of ADR

Study respondents were then asked to consider the number of times they had declined an offer from the opposing party to participate in ADR, and the factors which informed decisions to decline. Only 58 respondents (41.4 per cent) were able to answer this question. Responses must thus be interpreted in light of the low response rate.

Once again respondents were asked to indicate the relevance of particular factors in decisions to decline a proposal of ADR by way of a Likert scale of: "always relevant", "often relevant", "sometimes relevant", "rarely relevant" and "never relevant".

Some 56 respondents (96.6 per cent) suggested the fact that clients did not want to use ADR was either "always" (44.8 per cent); "often" (27.6 per cent); or "sometimes" relevant (24.1 per cent). Belief in strength of a client's case was also a prevalent factor cited as relevant in decisions to refuse ADR: "always" relevant by 6 respondents (10.3 per cent); "often" relevant by 19 respondents (32.8 per cent) and "sometimes" relevant by 14 respondents (24.1 per cent).

Given that litigation is predicated on a right/wrong dichotomy, where parties are confident in the strength of their legal case, this may be an important factor in rejecting ADR processes which are characterised by the notion of compromise (albeit, as noted, respondents sought to participate in ADR in circumstances in which a weakness in their clients' case was not paramount). Many of those intransigent parties, buoyed by a perception of strength in their case, may still ultimately settle out of court. In the latter stages of pre-trial court proceedings, however, those parties may perceive an increased leverage to extract a more favourable settlement than might be possible by ADR at an earlier juncture. Moreover, it may be argued that the mere fact that an opponent suggests ADR could be seen as a sign of weakness in their legal armoury, which in turn may render either the lawyer or client in receipt of the offer with a more favourable perception of their own case. This issue is returned to below.

The fact that clients did not want ADR was cited as a reason for rejection more commonly than any rationale grounded in a lawyer's belief of strength in the client's case. This suggests that irrespective of a lawyer's view of the voracity of a case, in many instances, the client's perspective may override this. Client barriers to ADR and the lawyer/commercial client relationship are revisited below. 
Allied to client reluctance is the fear alluded to above that the opposing side might not take part in good faith. Clearly some respondents shared this view. In terms of this factor, five respondents ( 8.6 per cent) viewed this as "always relevant"; 14 (24.1 per cent) as "often relevant" and 27 (46.6 per cent) as "sometimes relevant" in refusing an offer of ADR.

One further noteworthy consideration in rejecting ADR offers was the "belief that negotiation was capable of settling the case". This factor was *236 "always relevant" more than any other factor except that the client did not want ADR ("always relevant", 9 respondents (15.5 per cent)); "often relevant", 12 respondents (20.7 per cent); "sometimes relevant", 24 respondents (41.4 per cent)). If negation is imminent and viewed as likely to succeed then there may be no need to expend client monies on mediation. [FN32] If litigation has commenced, however, then negotiated settlement often occurs at a late stage in proceedings after which much time, money and effort has been expended. ADR proponents argue that mediation allows for an earlier settlement. [FN33] It may be, however, that such mediated settlement is a less informed one--parties may at an early stage know relatively little about the strengths and weaknesses of their case. Such issues may only become uncovered as litigation continues and in particular, after recovery of documents has occurred. At this point, cards are firmly laid on the table and a negotiated settlement can take place firmly in view of the respective strengths of parties' legal cases. Much perhaps depends on the legal complexity of the case at hand with arguably mediation being less appropriate at an early stage for more complex cases. In this sense it should be noted that the fact that ADR was rejected because of the "necessity for discovery of documents to first take place" received some support: "always relevant", one respondent ( 1.7 per cent); "often relevant", 14 respondents (24.1 per cent); "sometimes relevant", 23 respondents (39.7 per cent).

In terms of case-type, some support was found for the idea that particular sorts of cases, which could relate, for example, to dispute sphere or nature of remedy sought, may render recourse to ADR inappropriate. Four respondents ( 6.9 per cent) reported the case type being inappropriate as "always relevant", 12 respondents (20.7 per cent), "often relevant" and 29 respondents (50 per cent), "sometimes" relevant. In this sense, little is known about the applicability of mediation to different commercial dispute spheres. More research is needed to answer this question, but as we shall note below, mediation has been successfully utilised in Scotland, and 
thus by implication may be appropriate, in a wide range of different commercial dispute types.

Representing Clients in ADR

Only 48 respondents (34.8 per cent) had experience of representing clients in ADR. One respondent had acted as a representative in early neutral evaluation, but this aside, there was no other reported ADR experience outside mediation. Of the experienced respondents, 30 (62.5 per cent) had acted more than once in the representation capacity. This may lend support to the idea that lawyers, once they experience mediation, become repeat players in the process.

Respondents were first asked how many times that they had represented clients in ADR processes, broken up into different dispute areas. They were also asked to indicate the number of cases that "settled", "partially settled" or "did *237 not settle". Respondents reported that they had acted as client representatives in 147 cases across an array of commercial fields (broadly drawn). [FN34] The categories listed (including an "other" option), frequency of mediation and settlement rate are set out in Table 2 .

Table 2

Total Number of Number of Number of number cases cases cases of that that that did cases settled partially not settled settle

Breach of contract $\begin{array}{lllll}63 & 46 & 4 & \text { [FN35]11 }\end{array}$

Professional negligence [FN36] 2016221

Shareholder dispute $\begin{array}{llll}6 & 6 & 0 & 0\end{array}$

Personal injury 6510

General negligence $2 \quad 1 \quad 0 \quad 1$

Goods and services 7700 
Debt $5 \quad 5 \quad 0 \quad 0$

E-Commerce $6 \begin{array}{llll}6 & 0 & 0\end{array}$

Employment 181323

Construction [FN37] $444 \quad 0 \quad 0$

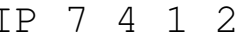

Partnership $2 \quad 0 \quad 1 \quad 1$

Professional relationship 10061

Total 1471131120

Breach of contract cases were the most commonly cited examples. Such cases, of course, represent very typical commercial disputes, but there may be particular reasons why breach of contract is deemed appropriate for resolution by mediation for which further research may assist in identifying. These results chime with comparable research which found that breach of contract and professional negligence represented a majority of commercial mediations in $\star 238$ England and Wales. [FN38] Although other research has suggested that personal injury cases were not generally appropriate for recourse of mediation, [FN39] the study found some evidence of successful mediation practice in respect of such disputes. Mirroring the findings of similar research, [FN40] the study did not suggest that particular dispute types, when referred to mediation, were less amenable to resolution therein. In this sense, there was generally little disparity reported with regard to settlement rates in different sorts of disputes, although in many cases the numbers involved were too small to make any observations.

The study revealed a settlement rate of 78.5 per cent [FN41] and when "partially settled" cases were included the rate rose to 84.4 per cent. These reported success 
rates stand up well to the high anecdotal figures which have been banded around by ADR service providers over the years--rates which cynics may have considered to be somewhat inflated. [FN42] Reported anecdotal settlement rates include between 74 and 78 per cent, CEDR; 85 per cent, The ADR Group; over 75 per cent, Catalyst Mediation; over 80 per cent, Core Mediation. [FN43]

Commercial Lawyers' Attitudes to ADR

The report then discussed respondents' views on certain policy issues relevant to the development of commercial ADR in Scotland. Respondents were provided with a number of statements and asked to indicate one of the following responses: "strongly agree", "somewhat agree", "somewhat disagree", "strongly disagree" or "don't know". For ease of analysis, the statements can be grouped into the following broad categories: the relationship between lawyers and ADR; the relationship between traditional dispute resolution processes and ADR; inherent deficiencies in ADR; and barriers to the development of ADR. [FN44]

\section{*239 Lawyers and ADR}

It can be argued that lawyers have no truck with ADR simply because it is not in their best interests. Traditional forms of dispute resolution may be dogged by protraction and expense for clients, which it has been contended, benefits the lawyer who has no incentive to promote a speedy, cost-effective form of dispute resolution. While this may be a cynical, unsophisticated argument, it has been suspected by commentators that lawyers have on one level or another acted as a barrier to ADR. Clark and Mays noted that for those active in the ADR field often the lack of ADR practice was due to lawyers' ignorance of, or indifference to ADR processes. [FN45] The Scottish Consumer Council suggested that "it may ... be that some solicitors fear that suggesting mediation to their clients will cause them to lose out financially". Moreover, there is some empirical evidence from England and Wales which suggests that certain lawyers have shied away from mediation because of the potential implications for their fees. [FN46]

Against this backdrop, respondents were asked to respond to the following statement: "lawyers will lose money if ADR becomes popular". The response was stark. From 135 respondents, none "strongly" agreed with the statement, 21 (15.6 per cent) "somewhat" agreed, 51 (37.8 per cent) "somewhat" disagreed and 36 (26.7 per cent) "strongly" disagreed. Taken at face value, the response 
casts doubt on the idea that Scottish commercial lawyers are seeking to stifle ADR on the grounds of a potential resulting reduction in income.

These findings may raise other concerns, however, along the lines that lawyers might perceive ADR as no more than some kind of cash-cow leading to a "milking" of ADR for the benefit of the profession, but to the detriment of others. [FN47] In this sense, previous research revealed a suspicion voiced by both non-lawyers and lawyers that defensive marketing in the Law Society of Scotland was afoot and that this professional body sought merely to maximise their members' interests in ADR, in the event of a proliferation of demand for such services. [FN48]

Study respondents' views on the following statement may hence be illustrative: "ADR is an opportunity for lawyers to offer further services to their clients". From 135 respondents, some 46 (34.1 per cent) "strongly" agreed with the statement, 72 (53.3 per cent) "somewhat" agreed, while only six ( 4.4 per cent) "somewhat" disagreed and four (3 per cent) "strongly" disagreed.

The respondents therefore strongly endorse the idea that ADR presents a new business opportunity for lawyers. There is nothing illegitimate in this, per se. That Scots lawyers should seek to embrace new markets is not surprising, particularly given the removal of their monopolies of late in areas such as $\star 240$ conveyancing and executries. There is clearly a role for lawyers to play in representing clients in mediation [FN49] and also an opportunity to act as mediators. The appropriateness of lawyers to act as mediators, however, is an issue of debate that cuts to the heart of what mediation practice entails. Previous research has indicated that tensions subsist between lawyer and non-lawyer mediators. [FN50] Aside from criticism regarding a high-jacking of mediation practice by lawyers and the squeezing out of others in the market place, concerns have been voiced regarding the suitability of lawyers to take on the mantle of mediation practice in view of the traditionally adversarial, partisan nature of their role, which may be at odds with the consensual nature of mediation. [FN51] Roberts, for example, suggested that it is:

"hazardous to seek mediators from within a profession whose members are traditionally most at home in an active, advisory and representative role". [FN52] Study respondents did not share this view. Given that respondents were lawyers, it may be of little surprise that on balance they viewed legal professionals as the best ADR neutrals. [FN53] While only eight from 137 respondents ( 5.8 per cent) "strongly" agreed with the statement that "[l]egal practitioners make the best ADR neutrals", some 59 (43.1 per cent) "somewhat" agreed. 
Only 29 respondents (21.2 per cent) "somewhat" disagreed with the statement and three ( 2.2 per cent) "strongly" disagreed. A significant number of respondents--38 (27.7 per cent)--did not know. Given the low mediation practice and variable ADR training rates the study uncovered, we might speculate that this response represents no more than a natural arrogance within the legal professional ranks [FN54] and not one rooted in any real appreciation of mediation and the role of the mediator therein. When this response was analysed against two factors--mediation practice and ADR training--interesting findings were uncovered.

Those who had received ADR training were slightly more likely to view that lawyers made the best ADR neutrals than respondents in general. [FN55] As noted above, respondents received ADR training most commonly through external mediation providers. Such Scottish providers include Core Mediation and Catalyst Mediation: essentially bodies provided by lawyers for lawyers and it may be of little surprise then that any inherent assumption that *241 lawyers are the natural inheritors of the mediator's crown endures amidst this lawyerdominated environment.

By contrast, mediation practice appeared to make respondents markedly less likely to view that lawyers made the best ADR neutrals. From 48 experienced respondents who answered the question, one (2.1 per cent) "strongly" agreed with the statement, 17 (35.4 per cent) "somewhat" agreed, 15 (31.3 per cent) "somewhat" disagreed and two ( 4.2 per cent) "strongly" disagreed. The responses here are hence much more balanced than the general set of responses. [FN56] At first blush it might be speculated that this shift could be attributed to negative experiences of lawyer mediators, but the very low reported negativity concerning the skills of mediators in the study militates against this idea. It may perhaps have been the case that some respondents have experienced mediations in which non-lawyer mediators excelled. The more balanced view regarding lawyers acting as ADR neutrals may rather, however, be merely rooted in a deeper appreciation of mediation borne out by exposure to the process in practice.

It has already been noted that the lawyer's traditional role may be anathema to the consensual ethos of mediation. Mediation practice in Scotland, however, may lend itself more appropriately to lawyers than one might suspect. In this sense, it may be that mediation in Scotland is more "evaluative" in nature than theory suggests. [FN57] Whereas "pure" mediators are mere facilitators of parties' communication and negotiation, [FN58] in an evaluative model of mediation: 
"a mediator focuses ... on the legal claims, assesses [their] strengths and weaknesses ... predicts the impact of not settling and pushes the parties to his/her evaluation of the appropriate settlement". [FN59] clearly lawyers may be well placed to offer this kind of service. In respect of large-scale commercial mediation, where each side is legally represented, arguably mediators need be less evaluative in practice. Indeed, evaluative models of mediation may stifle the scope for the development of creative, "win-win" solutions. Against this backdrop, legal knowledge and attributes may be less relevant than such skills as problem solving, dispute resolution, creativity and the ability to extricate parties from entrenched positions. [FN60] Many lawyers may hold such skills in spades, but so too will parties drawn from a *242 range of other professions. More research is needed to evaluate commercial mediation practice in scotland, the sorts of models mediators employ and the role of lawyers therein.

"Macho" Litigation Culture

In respect of whether mediation is being stifled because it is anathema to a "macho", adversarial culture that litigation lawyers work within, [FN61] the following statement was put to respondents: "if a lawyer participated more often in ADR his/her standing amongst colleagues would suffer". A stark response was obtained here. From 135 respondents, none "strongly" agreed with the statement, while only five ( 3.7 per cent) "somewhat" agreed, 39 (28.9 per cent) "somewhat" disagreed and 85 (63 per cent) "strongly" disagreed. Clearly the bulk of respondents were comfortable with the adoption of consensual forms of dispute resolution within the litigation environment. These findings are perhaps not surprising when one recognises that most cases brought to litigation settle extra-judicially and thus lawyers are commonly engaged in conciliatory activities throughout the course of disputes. Moreover, the inception of the commercial procedure in the court of session and certain sheriff courts, with its quasi-conciliatory ethos and emphasis on expediting settlement may assist the displacement of traditional adversarial litigation norms.

Similarly, despite assertions to the contrary, [FN62] few respondents supported the idea that suggesting ADR to the other side was a sign of weakness in a case: from 139 respondents, only 2 ( 1.4 per cent) "strongly" agreed and 14 (10.1 per cent) "somewhat" agreed, while 62 (44.6 per cent) "somewhat" disagreed and 56 (40.3 per cent) "strongly" disagreed. The two above responses coupled with increased ADR training and recognition within law 
firms may indicate that although mediation activity is rare, it is becoming a more accepted part of the scottish litigation culture.

$A D R$ and the courts

A key driver in the growth of mediation in commercial matters in England and Wales has been judicial embracement of the process in the aftermath of the post Civil Procedural Rules (CPR) regime. In this sense, the expediting of ADR is not merely a result of court referrals, but also in increased voluntary, ad hoc takeup against a backdrop of burgeoning judicial promotion. [FN63] Writing recently, Ross has suggested that at present judicial embracement of ADR in Scotland is patchy and that judicial drives to expedite ADR are necessary. [FN64] *243 There has been some limited recognition of ADR within Scottish litigation processes. For example, in commercial actions there are rules which allow the judiciary to refer a case to mediation. [FN65] A pilot mediation scheme for consumer disputes has also taken place in Edinburgh sheriff court. [FN66] On the back of the perceived success of the programme, the scheme has since been rolled out in other sheriff courts. [FN67]

Against this backdrop, study participants were asked to respond to two statements related to the interaction between the courts and ADR, the first being: "Scottish judges should refer more commercial cases to ADR". From 135 respondents, roughly the same agreed as disagreed: 13 respondents ( 9.6 per cent) "strongly" agreed with this statement and 41 (30.4 per cent) "somewhat" agreed, as opposed to 31 (23 per cent) who "somewhat" disagreed and 25 (18.5 per cent) who "strongly" disagreed. The second statement was "Making ADR a mandatory first step would be a positive development". The general response to this statement was less ambiguous, with a preponderance of respondents against mandatory recourse to ADR. Of 135 respondents, nine ( 6.7 per cent) "strongly" agreed, 28 (20.7 per cent) "somewhat" agreed, 41 (30.4 per cent) "somewhat" disagreed and 50 (37 per cent) "strongly" disagreed.

In general, while there was recognition that judicial promotion may help expedite the development of commercial $A D R$, mandatory recourse did not receive much support. Some forthright views were expressed. Ten respondents used the comments section on the questionnaire to argue that mediation was more effective when parties genuinely were committed and that mandatory recourse was anathema to the spirit of mediation. Many respondents, by contrast, advocated court referral and voluntary take-up. The difficulty with this position is that the schism 
between mandatory and non-mandatory referral to mediation is blurred. Although the authors are unaware of any Scottish jurisprudence on this issue, English experience is instructive. For example, under r.1.4(2) (e) of the CPR, English courts have been handed the task of "encouraging ADR". What this exactly entails has been left unelaborated, however, with no guidance provided in the CPR. Different courts have responded in different ways. In Shokusan $v$ Danovo, [FN68] it was held by Blackbourne $\mathrm{J}$. that a court had the power to order mediation even if one party was unwilling to take part. The Court of Appeal in Halsley $v$ Milton Keynes General NHS Trust, [FN69] however, took the view that compulsory referral would be contrary to the fundamental right of a litigant to have access to the courts and also potentially anathema to Art.6(1) of the European Convention on Human Rights. Nevertheless, the promotion of mediation by courts by way of costs sanctions may be tantamount to compulsion by the back door. In Dunnett $\mathrm{V}$ Railtrack Plc, [FN70] it was held that given what was deemed an "unreasonable" *244 refusal to attempt mediation, costs were not awarded against unsuccessful claimants. [FN71]

Some commentators have suggested that mandatory recourse to ADR is not problematic because the only obligation upon such parties is "to attend at a scene of a potential negotiation" and not to settle. [FN72] Moreover, it might be argued that compulsory recourse to mediation but with no duty to settle would not be contrary to Art.6(1), especially as this would occur against a general backdrop of encouraging settlement within the English litigation system. The view in Halsley that compulsion may infringe Art.6(1) was based on an interpretation of the decision in Deweer $v$ Belgium [FN73] in which the court of Human Rights held that where a shopkeeper alleged to have contravened a pricing law was offered the chance to make a payment in "friendly settlement" which would preclude the case going to trial, this amounted to a infringement of Art.6(1). It has been argued that Hasley is a misinterpretation of the law in this respect and that as the right to access to justice is an implied one within Art.6(1) it may be waived on occasion. [FN74] Nevertheless, the position of study respondents was clear that compulsory referral to ADR was generally not supported. The general view was that parties may subjugate their rights in favour of their interests if they perceive the latter to be more important in the circumstances, but there should no compulsion to do so. We share the view that any attempt to enmesh mediation within the fabric of traditional, judicial forms of dispute resolution should be tempered 
by this notion. It is perhaps telling that those respondents with experience of representing parties in ADR were no more in favour of compulsory than respondents in general--25 per cent "strongly" or "somewhat" agreed compared to 27.4 per cent, albeit that they were a little more likely to support the need for increased judicial referrals to ADR than general respondents--53.8 per cent "strongly" or "somewhat" agreed compared to 40 per cent. [FN75]

Developmental Issues and Barriers to ADR Propagation

Lack of Awareness

Despite the fact that respondents unanimously asserted that they could explain mediation to clients, respondents generally took the view that their fellow *245 lawyers knew little about ADR processes. In response to the statement "[t]here is a distinct lack of awareness regarding $A D R$ amongst the legal fraternity in scotland", from a 139 respondents, 25 (18 per cent) "strongly" agreed, and 70 (50.4 per cent) "somewhat" agreed as opposed to 24 (17.3 per cent) who "somewhat" disagreed and 10 ( 7.2 per cent) who "strongly" disagreed. How can these two sets of results be squared? First, those who did not respond to our survey may have shown lower levels of awareness regarding ADR than respondents. Moreover, as noted above, the fact that all respondents claimed to be able to describe mediation to a client may not translate into an informed appreciation of the process. It also appears that although awareness levels regarding ADR may be high on an individual lawyer or firm level, that knowledge is not being effectively propagated throughout the profession as a whole. Additionally, perhaps resistance from legal professionals to the use of ADR or the intransigence of their clients is being misinterpreted by other lawyers as a mere lack of awareness.

In respect of any widespread ignorance, there is clearly a role for the Law Society of Scotland (LSS) and Faculty of Advocates to reach out across their membership and propagate ADR. As noted above, the LSS has been criticised in the past for its defensive marketing strategy apropos ADR. Previous research found evidence of a lamentable lack of active ADR promotion by the LSS. [FN76] It was reported in 2003 that the LSS had not yet remedied the situation and "could not be accused of overegging ADR". [FN77] The study points to an information gap and suggests that more needs to be done by professional bodies in helping expedite the development of commercial mediation. 


\section{Training}

Respondents were largely in favour of compulsory training. In respect of the statement, "Training in ADR for Scottish lawyers should be compulsory", from 139 respondents, 16 (11.5 per cent) "strongly" agreed, 70 (50.4 per cent) "somewhat" agreed, 24 (17.3 per cent) "somewhat" disagreed and 15 (10.8 per cent) "strongly" disagreed. The study results indicated a strong link between training and practice of ADR. Respondents who had received training were much more likely both to suggest ADR to their clients and represent clients in mediations than non-trained respondents. [FN78]

\section{Client Resistance}

As noted above, where offers to engage in ADR were rejected it was reportedly largely caused by client reluctance. Moreover, in respect of failed mediations, predominantly such failure was blamed on clients. It might be speculated then that client ignorance/resistance to $A D R$ is the fundamental reason for the relative paucity of commercial mediations in Scotland. This is not a $* 246$ new assertion. Mays and Clark reported a view that consensual modes of dispute resolution might be anathema to litigants' desires for confrontation and conflict. [FN79] Moreover, the fact that mediation was something relatively untried and untested was also viewed as a barrier to wholesale acceptance by clients.

Such sentiments were shared by certain respondents. Some cited the fact that by the time ADR was suggested, clients were too polarised and in the words of one, did not want to "pussyfoot around". Another stated that clients "did not want to be guinea pigs". Generally, however, respondents did not strongly support the view that "the principal barrier to the development of ADR in Scotland is its negative perception among clients". In response to this statement, from 139 respondents, only nine ( 6.5 per cent) "strongly" agreed, while another 40 (28.8 per cent) "somewhat" agreed, while 41 (29.5 per cent) "somewhat" disagreed and 16 (11.5 per cent) "strongly" disagreed. With regard to the high incidence of clients rejecting ADR, or mediations failing because of client conduct, many respondents may have been of the view that there was nothing illegitimate in this behaviour--mediation may not be appropriate in all cases, and should not be foisted upon unwilling parties--and hence such client attitude/behaviour was not seen as the principal barrier to ADR's development. 
While consumer clients may lack knowledge and experience of litigation and hence may be less likely to take a realistic view of their dispute and possible dispute resolution outcomes, commercial clients, typically repeat players in the litigation game, may be better informed about their options, more realistic in their appraisals of possible dispute outcomes and hence more rational in their conduct. [FN80] The study suggested that nevertheless Scottish commercial clients are not embracing mediation on a significant level yet. Why might this be so? Even if mediation is not always appropriate it seems likely that given how common "door of the court settlement" is it will be apposite in a greater number of cases than are currently being mediated. As we noted earlier, lawyers are commonly viewed as gatekeepers to dispute resolution mechanisms. If lawyers are aware that mediation may eschew the costs, time and stresses of litigation, should it not be incumbent upon them to seek to override their clients' steely determination to continue with litigation, most likely to "door of the court" settlement, and steer these clients to mediation? The problem with this argument is that in respect of commercial clients, it may be based upon a false premise--namely that lawyers hold the power cards in the lawyer-client relationship. It has been contended that for various reasons, commercial clients [FN81] have become increasingly more dominant in the lawyer-client relationship.

It was suggested by Johnson that in general, professional groups could be classified into one of two categories, namely: "collegiate" and "patronage" *247 professions. He viewed that the legal profession fell into the collegiate camp, in that lawyers were able to exert power in the relationship over their clients. This he argued, stemmed primarily from the knowledge gap that subsisted between lawyers and clients. [FN82] The balance may have tilted of late in commercial legal practice. Recent times have seen a distinct growth in in-house legal counsel. Commercial clients may hence have become more informed legally and thus less reliant on external counsel. In-house lawyers do not merely carry out prophylactic activities, but may also influence the direction of general legal policy within their corporations. [FN83] Moreover, as repeat players, commercial clients will be able to learn more about dispute resolution processes and the legal profession (and lawyers' interests within the process) which may help shift the balance of power towards the client. Handler notes the schism between lawyers who represent commercial clients as opposed to consumers: "[s]trong, rich and confident clients direct their lawyers ... 
lawyers dominate the relationship when clients are poor, deviant, or unsophisticated." [FN84] US empirical studies have corroborated the notion that corporate lawyers rarely drive their clients' goals and rather are commonly seen as mere "tools" or "conduits" of their clients. [FN85]

These factors, along with reported client resistance both to and within ADR processes, suggest that bar any judicial drive to embrace ADR's development, the future of the development of commercial mediation may rest to a large extent on clients, irrespective of attempts made by litigation lawyers to propagate ADR. As we have noted, clients may often be justified in refusing to participate in ADR or failing to settle therein. Nevertheless, it can be contended that a skewed perception of clients towards mediation may exist which has blighted its development. Ross has argued that currently mediation is typically associated with negative characteristics such as weakness, compromise and concession. She contends that rather the process ought to be marketed as one which can meet the "selfish" needs of clients, more appropriately than traditional dispute resolution means. [FN86] A mediated settlement may in many cases meet clients' individual interests in a superior way than proceeding to litigation and/or "door of the court" settlement. Marketing mediation to focus squarely on meeting clients' "selfish" needs may help convince recalcitrant clients that there is something to be gained by engaging in the process.

The Appropriateness of Litigation

An additional factor stifling commercial ADR may be the appropriateness of civil litigation processes in Scotland. Although the traditional litigation system *248 in Scotland typically allows "secrecy and surprise" [FN87] and does not encourage settlement, it seems well recognised that the problems of cost and delay endemic to litigation in England and Wales are not so marked in Scotland. In particular, the commercial cause--a speedier procedure in which the judge undertakes a more pro-active role in assisting the parties to reach an early settlement--has received some approbation of late as an appropriate vehicle for the resolution of commercial disputes. [FN88] A handful of respondents in the comments section of the study were keen to bestow the virtues of the commercial cause and highlight the lack of need for mediation as a result.

In general, however, respondents took a less positive view of commercial litigation in scotland. In response to the statement, "litigation is generally well adapted to 
the needs and practices of the business community", from 134 respondents, only 6 (4.5 per cent) "strongly" agreed, while 35 (26.1 per cent) "somewhat" agreed, as opposed to 61 (45.5 per cent) who "somewhat" disagreed and 26 (19.4 per cent) who "strongly" disagreed.

When responses were gauged against mediation experience, significantly fewer respondents agreed that litigation served commercial clients' interests well. Only one of 48 respondents ( 0.2 per cent) who had represented clients in mediation "strongly" agreed with the statement, while another 7 (14.6 per cent) "somewhat" agreed as opposed to 28 (58.3 per cent) who "somewhat" disagreed and a further 12 (25 per cent) who "strongly" disagreed. It is of little surprise that in general those in the profession most disillusioned with traditional processes have sought to embrace mediation. Aside from positive attributes of mediation per se, the unsatisfactory nature of traditional dispute resolution from the lawyer's viewpoint may be a driving factor for the adoption of alternatives.

Conclusion

This article has analysed research which sought to inform assumptions relative to Scottish commercial ADR through empirical evidence. In particular, the study provided insights into the views of commercial lawyers on $\mathrm{ADR}$ and evidence of their current interaction therein. To some extent, the study findings are unsurprising and confirm much academic speculation. In this sense, the research revealed a small but significant measure of mediation practice across a wide array of commercial disputes in Scotland. In the main, mediation was successful and perceptions of those lawyers involved generally positive. Moreover, the majority of respondents, including those with no ADR experience, saw the potential benefits for their clients (and themselves) in adopting mediation. "Alternative" ADR processes, beyond mediation, seem dead in the water, however.

*249 The Scottish Consumer Council recently discussed the need for a cultural shift in the legal profession before ADR would develop. [FN89] One leading Scottish litigator was reported recently as saying that:

"[m]ediation is almost completely non-existent in [the commercial litigation] market ... that is because lawyers are taught to litigate and not to mediate. There is no cultural foundation for mediation in our legal system." [FN90]

The study revealed that although barriers to development remain, such a cultural shift may in fact be occurring within the profession, through a combination of pilot 
court mediation schemes, heightened mediation publicity and training take-up, increased university mediation provision, increased recommendation of ADR to clients and limited professional body endorsement. This cultural embracement of traditional dispute resolution players may chime with the notion that mediation should now be seen, as less an alternative to traditional dispute resolution, but rather as symbiotic to it.

The key that may unlock the door to the expediting of commercial mediation may to some extent lie with clients, however. Given the dominant position of commercial clients in the lawyer-client relationship, save any radical judicial endorsement of mediation, further publication of the potential benefits of mediation throughout the client base may be required before practice takes off. The confidential nature of mediation means that success stories are often kept under wraps and hence word-of-mouth propagation of the benefits of the process may be slow. It has been suggested, however, that client-driven mediation has already occurred in the United Kingdom with regard to particular dispute areas such as medical negligence, North sea hydrocarbon exploitation and UK-wide government departmental matters. [FN91] Selling mediation as a way in Ross's words to best meet clients' "selfish" needs might assist in the further propagation of mediation in Scottish commercial disputes. Mediation is no panacea. Further research is required on its appropriateness for different sorts of commercial disputes and the most apposite models of mediation practice to be employed therein. Even though reality remains lagging behind rhetoric for the time being, the future prognosis of commercial mediation in scotland seems a positive one. It also seems clear that in any widespread development of commercial mediation, lawyers, as key participants in traditional means of resolving disputes, may be just as prominent players in such alternatives.

FN Law School, University of Strathclyde; email: bryan.clarkestrath.ac.uk.

FN Law School, University of Strathclyde.

FN3. Referred to as "the study". For details of the full report, contact the authors on bryan.clarkestrath.ac.uk.

FN4. R. Mays and B. Clark, Alternative Dispute Resolution in Scotland (Edinburgh: Scottish Office Central Research Unit, 1999).

FN5. J. Lewis, The Role of Mediation in Family Disputes 
in Scotland (Edinburgh: Legal Studies Research Findings No.23, Scottish Office Central Research Unit, 1999); F. Myers \& F. Wasoff, Meeting in the Middle: A Study of Solicitors' and Mediators' Divorce Practice (Edinburgh: Legal Studies Research Findings No.25, Scottish Executive Central Research Unit, 2000).

FN6. J. Dignan and A. Sorsbury, Resolving Neighbour Disputes through Mediation in Scotland (Edinburgh: Scottish Office Central Research Unit, 1999).

FN7. See www.core-solutions.com.

FN8. See www.catalystmediation.co.uk.

FN9. M. Ross, "Mediation in Scotland: An Elusive Opportunity?" in A.N. Verlag \& O. Schmidt (eds), Global Trends in Mediation (2nd edn, 2006, advance copy made available to the authors for which we are grateful to Margaret Ross and Kluwer Publications); B. Clark, "A time for change? The development of commercial ADR in Scotland" (2003) 20 Scots Law Times 169-172; F. Macdonald, The Use of Mediation to Settle Civil Justice Disputes: a Review of Evidence (Legal Research Studies Programme No.50/2004).

FN10. See, e.g. E. Malcolm, "Breakpoint: Advantage Mediation" (2004) 49 J.L.S.S. 33; B. Clark, cited above fn.9; and J. Sturrock \& D. Semple, "Mediating a cultural revolution" (2001) 46 J.L.S.S. 21.

FN11. B. Clark and R. Mays, "Lawyers and ADR" (1996) 6 Juridical Review 389.

FN12. See Clark and Mays, cited above fn.11.

FN13. The definition of ADR utilised in the study included alternative forms of dispute resolution excluding traditional processes such as litigation, arbitration and negotiation.

FN14. Similar studies have been undertaken in England and Wales (see P. Brooker and R. Lavers, "Commercial and Construction ADR: Lawyers' Attitudes and Experience" (2001) 20 C.J.Q. 327) and Australia (A. Zariski, "Lawyers and Dispute Resolution: What do they think and know (and think they know)? Finding out through survey research" (1997) Murdoch University Electronic Journal of Law Vol.4, No.2 (1997)).

FN15. Mays and Clark, cited above fn.4. 
FN16. Two respondents did not answer the question.

FN17. Clark and Mays, cited above fn.11; H. Genn and A. Paterson, Paths to Justice Scotland (Hart, Oxford, 2001). B. Clark, cited above fn.6; M. Ross, "Mediating in the Shadow of Civil Procedural Law in Scotland: Away from 'Nursing Wrath' towards Nurturing Choice", Ohio State Journal of Dispute Resolution.

FN18. B. Clark and R. Mays "Regulating ADR: The Scottish Experience" (1996) 5 W.J.C.L.I. 199; Scottish Consumer Council, Consensus Without Court (2001), para.4.4.

FN19. H. Genn, Central London County Court Pilot Mediation Scheme: Evaluation Report (Lord Chancellor's Dept Research Series No.5/98), para.2.10.1.

FN20. Brooker \& Lavers, cited above fn.14.

FN21. See B. Clark \& R. Mays, "The development of ADR in Scotland" (1997) 16 C.J.Q. 26.

FN22. M. Ross, cited above fn.9. The authors are aware of new developments, such as a mediation elective at the Glasgow Graduate School of Law.

FN23. F. Macdonald, cited above fn.9.

FN24. See, e.g. G. Holliron, "ADR in commercial disputes" in R. Mackay \& S. Moody (eds), Green's Guide to Alternative Dispute Resolution in Scotland (1996).

FN25. Some respondents may have recommended ADR only once or twice and thus any distinction between "always", "often" and "sometimes" relevant is illusory.

FN26. F. Macdonald, cited above fn.9.

FN27. J. Fortham, "Settlement under the CPR: quicker but no cheaper" (2001) 89 I.H.L. 27.

FN28. Brooker and Lavers, cited above fn.14 at p.338.

FN29. Brooker and Lavers, "Construction Lawyers' Experience with Mediation Post-CPR" (2005) 21 Const. L.J. 19 at p.37.

FN30. Clark, cited above fn.9.

EN31. In Genn's study of the mediation pilot scheme in 
the English Court of Appeal (H. Genn, Court-based ADR initiatives for non-family civil disputes: The Commercial Court and the Court of Appeal (Lord Chancellor's Department. Research Series, No.1/02, 2002)), opt-in rates were low because one party had already "won" at first instance.

FN32. A. Evans, "Forget ADR: Think A or D" (2003) 22 C.J.Q. 230 at p.233.

FN33. The sheriff court commercial procedure (and similar Court of Session procedure) may, however, lead to earlier negotiated settlements--see E. Samuel, Commercial Procedure in Glasgow Sheriff Court (Scottish Executive Research Findings No.57/2005).

FN34. There will be double counting as in many cases both mediating parties will be legally represented and hence different respondents may have referred to the same case. Also, more than one respondent may have represented parties at the same time.

FN35. Two cases were on-going.

FN36. The disparity in figures here was due to respondent error.

FN37. The study did not target construction lawyers. It is hence likely that the small number of constructions mediations reported does not reflect the reality of practice.

FN38. Brooker \& Lavers, cited above fn.12.

FN39. See, e.g. Genn, cited above fn.19. The zero-sum nature of such disputes often leads to a "tendering" process that leads to settlement.

FN40. Such as the study by Brooker and Lavers, cited above fn.14.

FN41. The settlement rate was determined from 144 cases in which settlement outcome was known.

FN42. Success rates measured in terms of settlement may not necessarily correlate with respondent satisfaction. In the main, respondents were, however, well disposed towards their experiences within mediations. For completeness, it should be noted that the study revealed that failure to settle was almost always blamed on client factors, such as tactical use of mediation by clients, 
bad feeling between the parties and unwillingness of clients to compromise.

FN43. English empirical research regarding settlement rates is more mixed. Research by Brooker and Lavers (cited above fn.14) indicated a 77 per cent success rate for commercial mediations and a 67 per cent rate for construction mediations. Research by Genn (cited above fn.31) into mediation in the English Court of Appeal indicated a mere 45 per cent settlement rate.

FN44. For space restraints, the "don't know" responses have been omitted.

FN45. Clark and Mays, cited above fn.11.

FN46. Genn, cited above fn.19. Moreover, it is pertinent that take up was lowest in the LCC mediation scheme when both parties were represented--Genn, cited above fn.19 at pp. 25-27.

FN47. See, e.g. P. Robertshaw \& J. Segal, "The Milking of ADR" (1993) 12 C.J.Q. 23.

FN48. Mays and Clark, cited above fn.4.

FN49. See Clark and Mays, cited above fn.11; and M. Stone, "Representing clients in mediation: an essential new professional skill: Part 1" (2000) 45 J.L.S.S. 34 .

FN50. Mays and Clark, cited above fn.4.

FN51. S. Roberts, "Mediation in the lawyers' embrace" (1992) 55 M.L..R 258; Robertshaw \& Segal, cited above fn.76; and Mays and Clark, cited above fn.4.

FN52, ibid.

FN53. Given respondents' wide-spread awareness of mediation and negligible appreciation of other ADR processes and that virtually the only practised ADR form reported was mediation, most responses here are likely to pertain to mediation.

FN54. Roberts, cited above fn.51, talked about a "breathtaking arrogance" of lawyers' assumptions that they could effortlessly embrace ADR.

FN55. Some 51.9 per cent of respondents who had received ADR training agreed that lawyers made the best mediators, while 23.5 per cent disagreed. 
FN56. The differential is more stark if experienced respondents are compared to non-experienced respondents in which in relation to the proposition that lawyers made the best mediators, 6.9 per cent strongly agreed, 47.1 per cent somewhat agreed, 16.1 per cent somewhat disagreed and 1.1 per cent strongly disagreed.

FN57. Ross, cited above fn.17; R. McKay and A. Brown, Community Mediation in Scotland: A study of its implementation (Scottish Office CRU, 1998); Lewis, cited above fn. 5 .

FN58. S. Sibley and S. Merry, "Mediator Settlement Strategies" (1986) 8 Law and Policy Quarterly 7.

FN59. B. McAdoo and N. Welsh, "Does ADR really have a place on the lawyer's philosophical map?" (1997) 18 Hamline J. Pub. L. \& Pol'y 376 at p.389.

FN60. Recent research found the following most valued mediator qualities: understanding the dispute and parties; process management; encouraging communication; rapport building; personal qualities of the mediator; dealing with personalities; providing the right environment for settlement; and getting results--see CEDR, "What corporate clients want from ADR--and what they get", July 2004, available at: www.cedr.co.uk.

FN61. A view recorded in Mays and Clark, cited above fn.4. See also J. Riekert, "Alternative Dispute Resolution in Australian Commercial Disputes" (1990) 1 Australian Dispute Resolution Journal 31; J. Dieffenbach, "Psychology, Society and the Development of the Adversarial Posture" (1992) 7 Ohio State Journal of Dispute Resolution 261 (cited in Zarinski, cited above fn.14).

FN62. Scottish Consumer Council, cited above fn.18 at p.25.

FN63. See generally, S. Shipman, "Court Approaches to ADR in the Civil Justice System" (2006) 25 C.J.Q. 18.

FN64. Ross, cited above fn.7.

FN65. Rule of Court of Session 1994, r.47.12; Ordinary Cause Rules 1993, r.40.12A.

FN66. E. Samuel, Supporting Court Users: The in-court advice and mediation projects in Edinburgh Sheriff Court, 
Research Phase 2 (Scottish Executive CRU, Edinburgh, $2002)$.

FN67. Scottish Executive Press Release, August 22, 2005.

FN68. [2004] 1 W.L.R. 2985.

FN69. [2004] EWCA Civ 576.

FN70. [2002] EWCA Civ 303.

FN71. The court in Halsley sought to elaborate when it would be appropriate to award an adverse costs award against successful litigants who had rejected ADR. Such factors included the nature of the dispute, case merits, potential costs of ADR, previous attempts to settle, prospects of ADR success and whether ADR would delay the case. For a discussion of judicial encouragement of ADR post-CPR, see S. Shipman, cited above fn.63.

FN72. Wood Q.C., "Juggling Act" (2004) 18 The Lawyer 27 at p.27; T. Allen, "Rewewing civil justice in Scotland: An English review of the Scottish Consumer Council's call for review!", February 2006, available at: www. cedr.co.uk.

FN73. (A/35) [1980] E.C.C. 169 (ECHR) .

FN74. For a discussion of Halsley and Deweer: B. Tronson, "Mediation orders: do the arguments against them make sense?" (2006) C.J.Q. 411.

FN75. Linked to compulsion is the issue of inherent deficiencies in ADR processes, such as power imbalances, lack of coercive power and diversion from judicial settlement. Respondents generally gave short shrift to such concerns.

FN76. Mays and Clark, cited above fn.4.

FN77. Clark, cited above fn.9 at p.171.

FN78. For non-trained respondents, 8 (14 per cent) represented clients in mediation, while 23 (40.4 per cent) had recommended ADR to clients. For trained respondents, 39 (47 per cent) had represented clients in mediation, while 72 (86.7 per cent) had recomended ADR to clients.

FN79. Mays and Clark, cited above fn.4. 
FN80. Clients whose own operations are orderly, rational, efficient and reflective might prefer a method of dispute resolution that operates in a highly rational, efficient way--see R. Redmount \& F. Mosten, "Client centred consultation and ADR" (1995) 20 I.L.P. 28.

FN81. As opposed to consumers.

FN82. T. Johnson, Professions and Power (Macmillan, London, 1972).

FN83. Cain and Harrington, Lawyers in a Post-modern world (Oxford University Press, Buckingham, 1994).

FN84. J. Handler, Social Movements and the Legal System: A Theory of Law Reform and Social Change (1978) at p.25.

FN85. See, e.g. R.A. Kagan \& R.E. Rosen, "On the Social Significance of Large Law Firm Practice" (1985) 37 Stan. L. Rev. 399; E. Spangler, Lawyers for Hire: Salaried Professionals at Work (1986) at p.64 reviewed in L. Mather, "What do clients want? What do lawyers do?" (2003) 52 Emory L.J. 1065.

FN86. Ross, cited above fn.17.

FN87. ibid., p.1.

FN88. Samuel, cited above fn.33, reported positive feedback from participants in the Glasgow sheriff court commercial cause.

FN89. Scottish Consumer Council, cited above fn.18.

FN90. R. Mackenzie quoted in R. Draycott, "Natural Born Killer" (2004) The Firm Magazine, available at:

www.firmmagazine.com

FN91. Ross, cited above fn.17 at p.2.

CJQ 2007, 26(Apr), 228-249 